\title{
Studies on Mutagenic Effectiveness and Efficiency of Gamma Rays in Greengram [Vigna radiata (L.) Wilczek]
}

\author{
Prasanta Kumar Majhi ${ }^{1 *}$ and Suma C. Mogali ${ }^{2}$
}

${ }^{1}$ Department of Genetics and Plant Breeding, College of Agriculture, University of Agricultural Sciences, Dharwad-580005, Karnataka, India

${ }^{2}$ AICRP on MULLaRP, Main Agricultural Research Station, College of Agriculture, University of Agricultural Sciences, Dharwad-580005, Karnataka, India

*Corresponding author

\section{A B S T R A C T}

Keywords

Mutagen, gamma rays, mutagenic effectiveness, mutagenic efficiency, mutation frequency

\section{Article Info}

Accepted:

12 February 2020

Available Online:

10 March 2020
The mutagenic effectiveness and efficiency of gamma rays was studied on greengram breeding lines with dose of $20 \mathrm{kR}$ and $100 \mathrm{kR}$ for creation of desirable variability. These two parameters are the measures of usefulness of a particular mutagen for a particular crop genotype. Highest mutation frequency was found in the breeding lines of DGGV-2 $\times$ IPM-410-3 $(11.42 \%)$ and DGGV-2 $\times$ SML-1815 (7.27\%) with $100 \mathrm{kR}$. The mutagenic effectiveness was highest in the breeding lines of DGGV-7 $\times \mathrm{V}-02-709$ with 0.25 at the dose $20 \mathrm{kR}$, whereas the lowest (0.07) was observed in DGGV-2 $\times$ SML-1815 with $100 \mathrm{kR}$. The average mutagenic efficiency was highest in the breeding lines of DGGV-7 $\times$ V-02-802 (0.39). Hence, the mutagenic effectiveness was decreased with increased dose of mutagen, while the mutagenic efficiency was reported higher in lower dose of mutagen as the higher dose causes reduction in germination percentage and more lethal plants.

\section{Introduction}

Greengram [Vigna radiata (L.) Wilczek] is a short duration grain legume crop occupied the position of third most important pulse crop after chickpea and pigeonpea. It can be grown in varying climatic conditions and having the ability to withstand drought. It can be cultivated during all three seasonsviz., kharif, rabi and summer in different parts of the country as a sole crop or as an intercrop (green manure).

Greengram has easily digestible protein and contains approximately $25-28 \%$ protein, 62$65 \%$ carbohydrates and $3.5-4.5 \%$ fiber on dry weight basis (Gowda et al., 2015). Lysine value in mungbean is comparatively high; 
hence the protein is an excellent complement with rice for balance human diet.

Mutation is the sudden heritable changes in the organisms generally in the structural changes in the genes which are not caused due to any genetic recombination and crossing over. It is produced by changing the base sequence of genes either spontaneously or by induced mutation after treating with seeds or vegetative parts with mutagen. Induced mutation breeding has been recognized as a valuable supplement to conventional breeding in crop improvement. A number of chemical and physical mutagens are used in crop improvement programme for induction of useful mutants in a number of crops (Sange et al., 2011 and Bashir et al., 2013) and high yielding new varieties produced by gamma rays and EMS was observed by Khatri et al., 2005. In plants, gamma rays are known to influence plant growth and development by inducing cytological, genetical, biochemical, physiological and morphogenetic changes in the cells and tissues.

Mutagenic effectiveness and efficiency are the measures of usefulness of a particular mutagen for mutation breeding in a particular crop genotype. These two are the base parameters to predict the mutagenic potency of any mutagen. The prior information of comparative effectiveness and efficiency of various mutagens facilitate the selection, which is essential to recover high frequency of desirable mutations.

Although, effectiveness and efficiency of a particular mutagen are completely different properties but they together define the usefulness of any mutagen. It is not necessary that an effective mutagen shall be an efficient one also. The value of effectiveness and efficiency estimation depends on various factors like biological, environmental and chemical that can modify mutation rate of different mutagens (Konzak et al., 1965). A highly effective mutagen may not necessarily show high efficiency and vice-versa. The higher efficiency of a mutagen indicates relatively less biological damage (seedling injury, pollen sterility and ovule sterility etc.) in relation to the doses of mutagen (Tariq et $a l$. , 2008). Hence, it is necessary to better understand the efficiency and effectiveness of different mutagens for creation of desirable variability with higher frequency and spectrum. Hence, it is essential to evaluate the efficiency, effectiveness and factor of effectiveness of gamma rays in green gram. Therefore, the present investigation was undertaken to assess the mutagenic effectiveness and efficiency oftwo different doses of gamma rays at different levels of morphological characters in greengram.

\section{Materials and Methods}

The $\mathrm{F}_{2}$ seeds derived from the following four different crosses are mentioned below in Table 1; were irradiated withgamma rays in kharif-2017 for creation of desirable variability and for driving the force of selection to desirable mutants and the field experiment was carried out at Experimental plot, AICRP on MULLaRP, Main Agricultural Research Station, College of Agriculture, University of Agricultural Sciences, Dharwad, Karnataka, India.

\section{Gamma rays irradiation and development of $\mathrm{F}_{2} \mathrm{M}_{1}$ generation}

The well dried, genetically pure, disease free and viable seeds from each cross were sent to Bhabha Atomic Research Centre, Mumbai; for gamma rays irradiation. The pedigree, number of seeds from each cross and the dose of irradiation is mentioned below in Table 1 . The irradiated seeds were sown to develop the $\mathrm{F}_{2} \mathrm{M}_{1}$ generation during kharif-2017 along 
with their respective checks. All the cultural practices including irrigation, weeding, manuring and plant protection practices were monitored to raise a good crop.In $\mathrm{F}_{2} \mathrm{M}_{1}$ generation; the germination reduction, reduction in seedling height and plant survivality was recorded and considered as Injury (I) and Lethality (L), (Sharma, et al., 2005 and; Singh and Singh, 2001). The fertile $\mathrm{F}_{2} \mathrm{M}_{1}$ plants were harvested separately at maturity and seeds were sown in plant to row method to raise the $\mathrm{F}_{2} \mathrm{M}_{2}$ generation along with the controls.

\section{Observations recorded $F_{2} M_{1}$ generation}

The observation for germination was taken on $7^{\text {th }}, 15^{\text {th }}$ and $30^{\text {th }}$ day of sowing. Higher number of seeds was germinated at $20 \mathrm{kR}$ as compared to $100 \mathrm{kR}$ dose of gamma rays. The plants which survived beyond 30 days grew up to maturity, while a few plants died in between $15^{\text {th }}$ and $30^{\text {th }}$ day (Table 3). The following observations were recorded from the $\mathrm{F}_{2} \mathrm{M}_{1}$ generation duringkharif-2017.

\section{Days to 50 percent germination count}

The numbers of days from the date of sowing to the date of 50 per cent seeds germinated in each plot was counted and recorded.

\section{Plant count per plot after 15 days of germination}

The number of plants survived after 15 days of germination count was counted and recorded in each plot to calculate field emergence.

\section{Plant count per plot after 30 days of germination}

The number of plants survived after 30 days of germination was counted and recorded in each plot to calculate survival percentage.

\section{Field emergence percentage}

Observation on field emergence was recorded on $15^{\text {th }}$ days after sowing. Field emergence percentage was calculated by using the following formula.

$$
\text { Field emergence per cent }(\%)=\frac{\text { Number of plants emerged }}{\text { Total number of seeds sown }} \times 100
$$

\section{Survival percentage}

Seedlings survived on 30 days after sowing (DAS) were counted and survival per cent was calculated by using the following formula.

$$
\text { Survival percentage }(\%)=\frac{\text { Number of seedlings survived up to } 30 \text { days }}{\text { Total number of seeds germinated }} \times 100
$$

\section{Mutagenic effectiveness}

The mutagenic effectiveness was calculated based on the formula given by Konzak et al., (1965).

Mutagenic effectiveness $=\frac{\text { Mutation frequency }(\mathrm{MF})}{\text { Dose of physical mutagen }(\mathrm{kR})} \times 100$

Where,

$\mathrm{MF}=$ Mutation frequency

$\mathrm{kR}=$ unit of gamma radiation (kilo rad)

\section{Mutagenic efficiency}

The mutagenic efficiency was determined by using the formula given by Konzak et al., (1965).

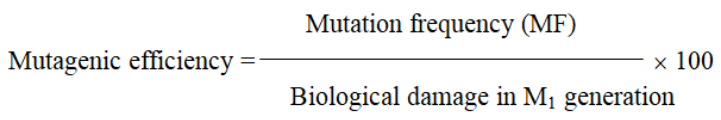

Where, Biological damage (L and I) 
$\mathrm{L}=\%$ of lethality in $\mathrm{M}_{1}$ generation

$\mathrm{I}=\%$ of seeding injury in $\mathrm{M}_{1}$ generation

\section{Development of $\mathrm{F}_{2} \mathrm{M}_{2}$ generation}

The seeds from $\mathrm{F}_{2} \mathrm{M}_{1}$ generation of kharif2017 were harvested individual plant basis and sown in summer-2018 to develop the $\mathrm{F}_{2} \mathrm{M}_{2}$ population in an augmented design. Similar agronomical practices also followed to raise a healthy crop.The plants were screened for chlorophyll mutation (eg.-albina, xantha, chlorine and striata) along with the other viable morphological mutations.

\section{Results and Discussion}

\section{Biological damages and survival per cent in $\mathrm{F}_{2} \mathbf{M}_{1}$ generation}

In the present investigation, germination reduction and seedling lethality were recorded in $\mathrm{F}_{2} \mathrm{M}_{1}$ generation. After 7 days of sowing, the number of seeds germinated was counted in each mutant breeding lines and it was observed that the cross derivatives of DGGV$7 \times \quad \mathrm{V}-02-802$ have shown highest germination of 94.80 per cent, followed by the cross derivatives of DGGV-7 $\times \mathrm{V}-02-709$ which shown 87.60 per cent with dose $20 \mathrm{kR}$. Less than $50 \%$ germination was observed for the breeding lines of the cross DGGV-2 $\times$ SML-1815 (37.05\%) and DGGV-2 $\times$ IPM410-3 (23.98\%) (Table 2).

The field emergence was highest for the cross derivatives of DGGV-7 $\times$ V-02-802 $(81.6 \%)$ at $20 \mathrm{kR}$. The cross derivatives of DGGV $-7 \times$ V-02-709, DGGV-2 $\times$ IPM-410-3 and DGGV-2 $\times$ SML-1815 have shown the field emergence percentage of 77.6, 18.9 and 30.94 per cent respectively.

The highest survival per cent was observed for the breeding lines of DGGV-7 $\times \mathrm{V}-02-802$ with $71.94 \%$. This cross derivative was also shown highest field emergence. The breeding lines derived from the crosses DGGV $-7 \times \mathrm{V}$ 02-709, DGGV-2 $\times$ IPM-410-3 and DGGV-2 $\times$ SML-1815 were shown 54.79, 59.32 and 62.5 per cent survival respectively with dose of $100 \mathrm{kR}$ (Table 3$)$.

The lowest germination reduction was recorded in the cross derivatives of DGGV$7 \times \mathrm{V}-02-709(4.2 \%)$ and DGGV-7 $\times \mathrm{V}-02-$ $802(12.4 \%)$ which were treated with $20 \mathrm{kR}$ dose, whereas; the cross derivatives of DGGV-2 $\times$ IPM-410-3 and DGGV-2 $\times$ SML1815 have recorded higher germination reduction of 76.01 and 62.94 per cent respectively with $100 \mathrm{kR}$.

The lethality parentage was calculated by counting the dead seedlings and expressed as lethal plant percentage. Lowest lethality was observed for the cross derivative of DGGV-7 $\times$ V-02-802 $(28.81 \%)$. The lethality per cent was recorded for the cross derivatives of viz; DGGV-7 × V-02-709, DGGV-2 × IPM-410-3 and DGGV-2 $\times$ SML-1815 with $45.20,40.67$ and 37.50 per cent.

Highest mutation frequency was found in the breeding lines of DGGV-2 $\times$ IPM-410-3 $(11.42 \%)$ and DGGV-2 $\times$ SML-1815 (7.27 $\%$ ) with $100 \mathrm{kR}$ dose of irradiation but at 20 $\mathrm{kR}$ the mutation frequency was observed comparatively low i.e. 5.00 and $2.93 \%$ for the lines of DGGV-7 $\times \mathrm{V}-02-802$ and DGGV$7 \times$ V-02-709 respectively (Table 4). The result of mutation frequency in present study was in accordance with the results obtained by Kumar et al., (2003) in lima bean.

The results obtained from the present study were reinforced with the findings of Bhosle and Kothekar (2010) in cluster bean and;Girija and Dhanavel (2009) on cowpea. The higher dose of mutagens generally causes increased lethality which is proved by the findings of the above. The probable cause for 
increased pollen sterility and poor seed set might be due to meiotic irregularities.

Mutagenic effectiveness and efficiency of gamma rays on greengram breeding lines in $\mathbf{F}_{2} \mathbf{M}_{1}$ generation

The mutagenic effectiveness and efficiency of mutagen and their doses are prerequisites for induction and utilization of mutation (Sharma et al., 2005). Mutagenic effectiveness is a measure of the frequency of mutations induced by the unit dose of the mutagen, while efficiency refers to the mutation rate in relation to biological damage such as seedling injury, pollen sterility, lethality in $\mathbf{M}_{1}$ generation. Thus, mutagenic effectiveness and efficiency gives an idea to prior evaluation of a particular mutagen.

The mutagenic effectiveness was highest in the cross derivative of DGGV-7 $\times \mathrm{V}-02-709$ $(0.25)$ at $20 \mathrm{kR}$ whereas, the lowest mutagenic effectiveness (0.07) was observed from DGGV-2 $\times$ SML-1815 which was treated with $100 \mathrm{kR}$. The other two cross derivatives viz; DGGV-7 $\times \mathrm{V}-02-802$ and $\mathrm{DGGV}-2 \times$ IPM-410-3 shown mutagenic effectiveness of 0.14 and 0.11 respectively (Table 5 and Fig 1). The results were supported by the findings of several other workers; Bhosle and Kothekar (2010) and Dube et al., (2011) in cluster bean when treated with gamma rays. They also reported that the effectiveness goes on decreasing with increased dose of mutagen.
The average mutagenic efficiency was highest in the breeding lines of DGGV-7 $\times \mathrm{V}-02-802$ (0.39) and lowest was 0.15 in DGGV-7 $\times \mathrm{V}$ 02-802. The cross derivatives of DGGV-7 $\times$ V-02-709 and DGGV-2 $\times$ IPM-410-3 have recoded 0.25 and 0.17 mutagenic efficiencies. The mutagenic efficiency with respect to germination reduction was found to be higher as compared to the lethal plants. The mutagenic efficiency in relevance to germination reduction was 0.40 and 0.69 in DGGV-7 $\times$ V-02-709 and DGGV-7 $\times$ V-02802 with $20 \mathrm{kR}$, while it was 0.15 and 0.11 in DGGV-2 $\times$ IPM-410-3 and DGGV-2 $\times$ SML1815 with $100 \mathrm{kR}$ respectively.

Compared to the lethal plant, the mutagenic efficiency was found 0.11 and 0.10 for the breeding lines of DGGV-7 $\times \mathrm{V}-02-709$ and DGGV-7 $\times$ V-02-802 with $20 \mathrm{kR}$, while 0.20 and 0.19 in DGGV-2 $\times$ IPM-410-3 and DGGV-2 $\times$ SML-1815 with 100 kR respectively (Table 5 and; Fig 2 and 3 ). Similar results were also reported by Bhosle and Kothekar (2010) in cluster bean, Mullainathan andUmavathi (2014) on chickpea,Patil et al., (2015) on rice bean, Morel and Borkar (2016) on rajmas and;Rafiul and Samiullah (2017) on lentil. The findings of the above workers also showed conformity with the present investigation for the mutagenic effectiveness and efficiency of gamma rays on different crops.

Table.1 Materials used for gamma rays irradiation

\begin{tabular}{|c|c|c|c|}
\hline Sl. No. & Pedigree & Doses of Mutagen (kR) & $\begin{array}{c}\text { Number of seeds } \\
\text { treated }\end{array}$ \\
\hline 1. & DGGV-7 $\times$ V-02-709 & 20 & 500 \\
\hline 2. & DGGV-7 $\times$ V-02-802 & 20 & 500 \\
\hline 3. & DGGV-2 $\times$ IPM-410-3 & 100 & 492 \\
\hline 4. & DGGV-2 $\times$ SML-1815 & 100 & 475 \\
\hline
\end{tabular}


Table. 2 Germination counts on $7^{\text {th }}$ DAS and plant count after $15^{\text {th }}$ and $30^{\text {th }}$ days of germination after gamma rays irradiation (kharif2017)

\begin{tabular}{|c|c|c|c|c|c|c|c|}
\hline $\begin{array}{c}\text { Sl. } \\
\text { No. }\end{array}$ & Pedigree & $\begin{array}{c}\text { Total } \\
\text { number } \\
\text { of seeds } \\
\text { sown }\end{array}$ & $\begin{array}{c}\text { Dose } \\
\text { (kR) }\end{array}$ & $\begin{array}{c}\text { First } \\
\text { germination } \\
\text { count (after } \\
\text { 7 days after } \\
\text { sowing) }\end{array}$ & $\begin{array}{c}\text { Plant count } \\
\text { per plot (after } \\
\text { 15 days of } \\
\text { germination) }\end{array}$ & $\begin{array}{c}\text { Plant count } \\
\text { per plot } \\
\text { (after 30 } \\
\text { days of } \\
\text { germination) }\end{array}$ & $\begin{array}{c}\text { Germination } \\
\text { percentage }\end{array}$ \\
\hline 1. & DGGV-7 $\times$ V-02-709 & 500 & 20 & 438 & 388 & 240 & 87.60 \\
\hline 2. & DGGV-7 $\times$ V-02-802 & 500 & 20 & 474 & 408 & 341 & 94.80 \\
\hline 3. & DGGV-2 $\times$ IPM-410-3 & 492 & 100 & 118 & 93 & 70 & 23.98 \\
\hline 4. & DGGV-2 $\times$ SML-1815 & 475 & 100 & 176 & 147 & 110 & 37.05 \\
\hline
\end{tabular}

*DAS- Days after sowing

Table.3 Field emergence percentage and survival percentage in $\mathrm{F}_{2} \mathrm{M}_{1}$ generation after gamma rays irradiation (kharif-2017)

\begin{tabular}{|c|c|c|c|}
\hline $\begin{array}{c}\text { Sl. } \\
\text { No. }\end{array}$ & Pedigree & $\begin{array}{c}\text { Field emergence } \\
\text { percentage }(\boldsymbol{\%})\end{array}$ & Survival (\%) \\
\hline 1. & DGGV-7 $\times$ V-02-709 & 77.6 & 54.79 \\
\hline 2. & DGGV-7 $\times$ V-02-802 & 81.6 & 71.94 \\
\hline 3. & DGGV-2 $\times$ IPM-410-3 & 18.9 & 59.32 \\
\hline 4. & DGGV-2 $\times$ SML-1815 & 30.94 & 62.5 \\
\hline
\end{tabular}

Table.4 Mutation frequency, number of seeds not germinated and number of seedlings died in $\mathrm{F}_{2} \mathrm{M}_{1}$ generation after gamma rays irradiation (kharif-2017)

\begin{tabular}{|l|l|c|c|c|c|c|c|}
\hline $\begin{array}{c}\text { Sl. } \\
\text { No. }\end{array}$ & Pedigree & $\begin{array}{c}\text { Number of seeds } \\
\text { not germinated }\end{array}$ & $\begin{array}{c}\text { Number of } \\
\text { seedlings } \\
\text { died(L) }\end{array}$ & $\begin{array}{c}\text { Putative } \\
\text { mutants } \\
\text { in M1 }\end{array}$ & $\begin{array}{c}\text { Mutation } \\
\text { Frequency } \\
\text { (MF \%) }\end{array}$ & R (\%) & L (\%) \\
\hline 1. & $\begin{array}{c}\text { DGGV-7 } \times \\
\text { V-02-709 }\end{array}$ & 62 & 198 & 12 & 5.00 & 12.4 & 45.20 \\
\hline 2. & $\begin{array}{c}\text { DGGV-7 } \times \\
\text { V-02-802 }\end{array}$ & 21 & 138 & 10 & 2.93 & 4.2 & 28.81 \\
\hline 3. & $\begin{array}{c}\text { DGGV-2 } \times \\
\text { IPM-410-3 }\end{array}$ & 374 & 48 & 8 & 11.42 & 76.01 & 40.67 \\
\hline 4. & $\begin{array}{c}\text { DGGV-2 } \\
\text { SML-1815 }\end{array}$ & 299 & 66 & 8 & 7.27 & 62.94 & 37.50 \\
\hline
\end{tabular}

Where, R \%- Reduction of germination (Per cent of seeds not germinated), L \%- Lethality per cent (Number of seedlings died) 
Table.5 Mutagenic effectiveness and efficiency of gamma rays in green gram in $\mathrm{F}_{2} \mathrm{M}_{1}$ generation (Kharif-2017)

\begin{tabular}{|c|l|c|c|c|c|}
\hline S.No. & \multicolumn{1}{|c|}{ Pedigree } & $\begin{array}{c}\text { Mutagenics } \\
\text { Effectiveness }\end{array}$ & \multicolumn{3}{|c|}{ Mutagenic Efficiencies } \\
\hline & & MF/kR & MF/R & MF/L & Average \\
\hline 1. & DGGV-7 $\times$ V-02-709 & 0.25 & 0.40 & 0.11 & 0.25 \\
\hline 2. & DGGV-7 $\times$ V-02-802 & 0.14 & 0.69 & 0.10 & 0.39 \\
\hline 3. & DGGV-2 $\times$ IPM-410-3 & 0.11 & 0.15 & 0.20 & 0.17 \\
\hline 4. & DGGV-2 $\times$ SML-1815 & 0.07 & 0.11 & 0.19 & 0.15 \\
\hline
\end{tabular}

*MF- Mutation Frequency, kR- kilo Rad (Physical mutagen dose), R- Germination reduction or Number of seeds not germinated and L- Lethal plants or Number of seedlings died

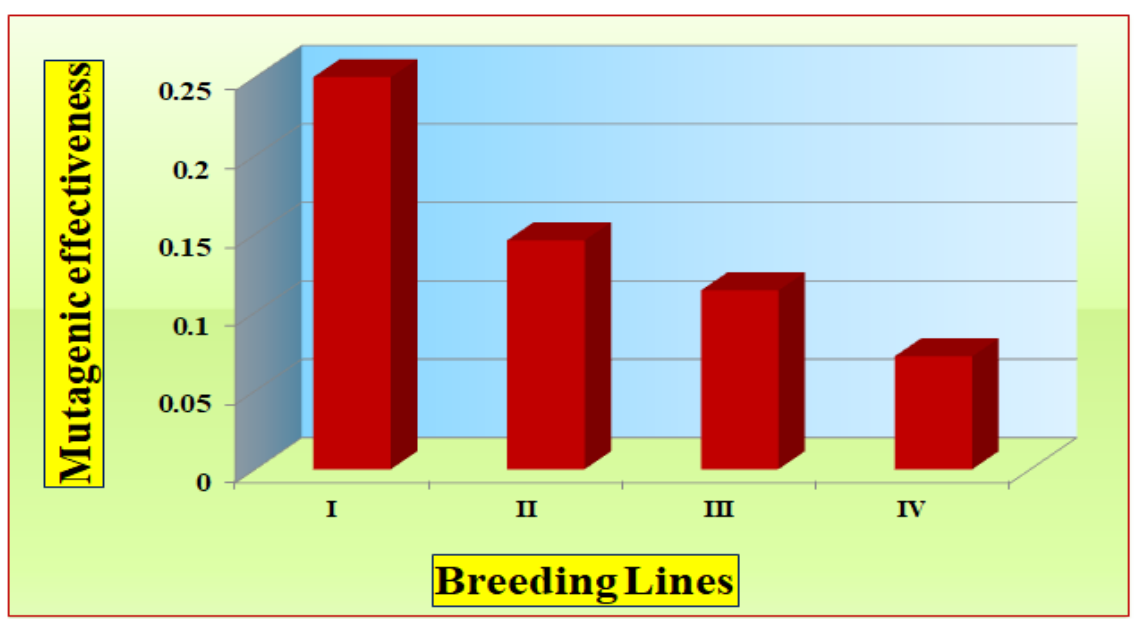

Fig.1 Mutagenic effectiveness in $\mathrm{F}_{2} \mathrm{M}_{1}$-generation of greengram breeding lines [Roman letter indicates; I- DGGV-7 × V-02-709 (20 kR), II- DGGV-7 × V-02-802 (20 kR),

III- DGGV-2 $\times$ IPM-410 $(100 \mathrm{kR})$ and IV- DGGV-2 $\times$ SML-1815) $(100 \mathrm{kR})]$

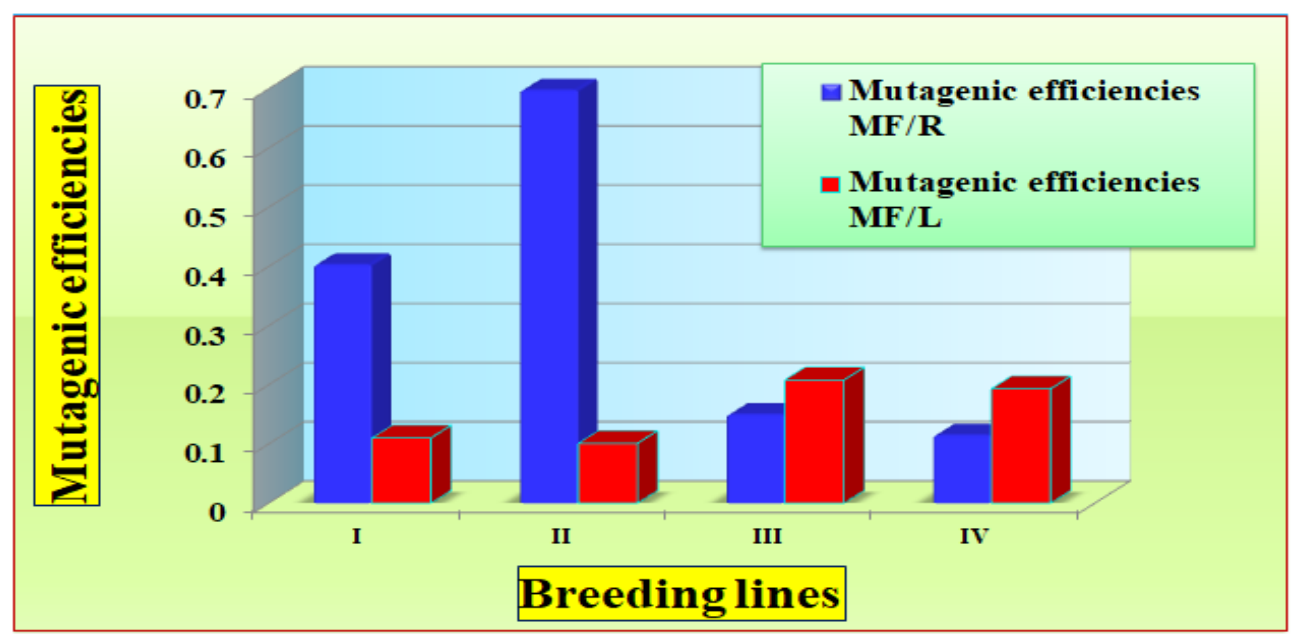

Fig.2 Mutagenic efficiencies in $\mathrm{F}_{2} \mathrm{M}_{1}$ - generation of greengram breeding lines [Roman letter indicates; I- DGGV-7 × V-02-709 (20 kR), II- DGGV-7 × V-02-802 (20 kR), III- DGGV-2 $\times$ IPM-410(100 kR) and IV- DGGV-2 × SML-1815) $(100 \mathrm{kR})], \quad$ MF/R-Mutagenic frequency 


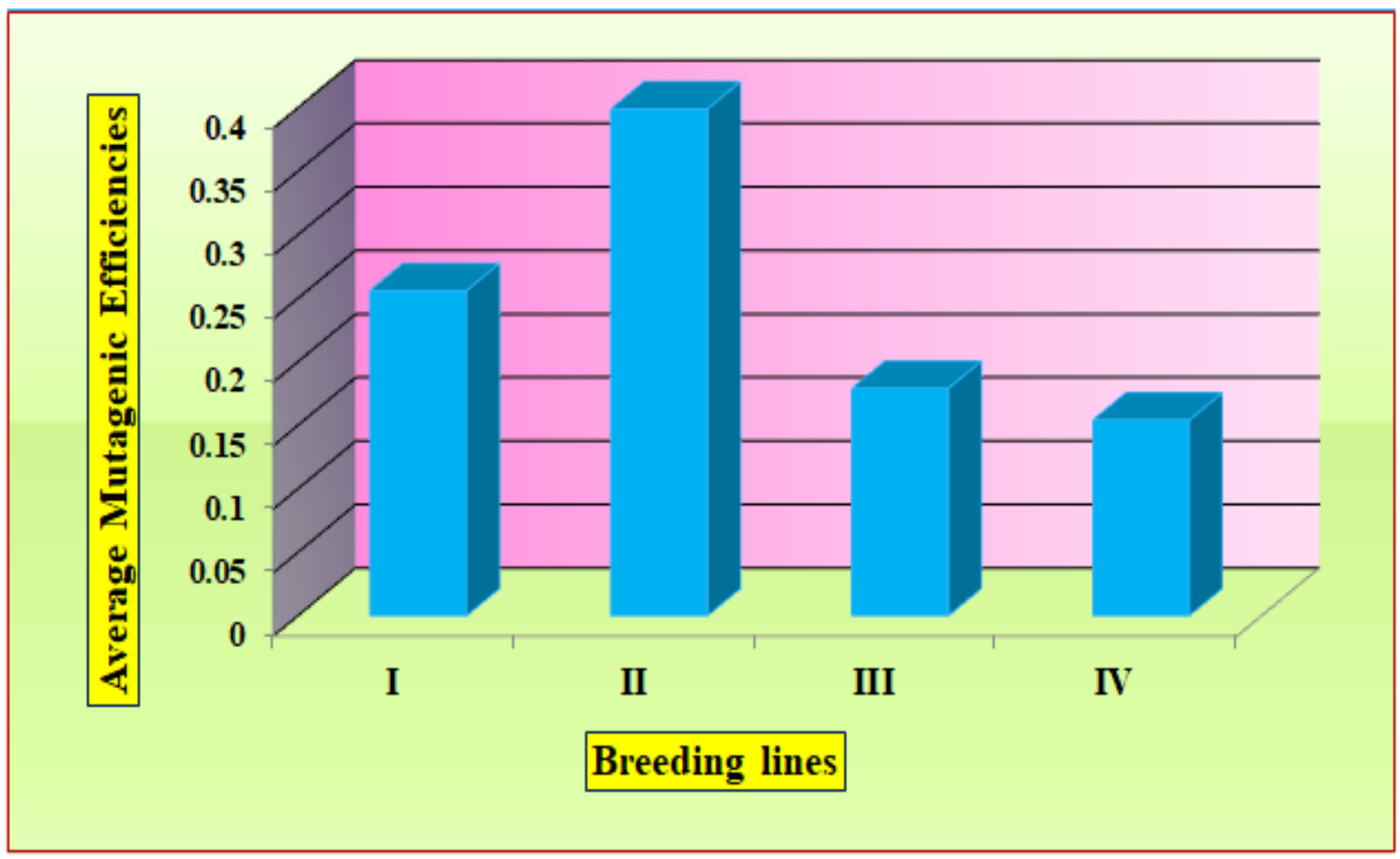

w.r.t. germination reduction and $\mathrm{MF} / \mathrm{L}-\mathrm{Mutagenic}$ frequency w.r.t. lethal plants

Fig.3 Average Mutagenic Efficiencies in $\mathrm{F}_{2} \mathrm{M}_{1}$ - generation [Roman letter indicates;

I- DGGV-7 × V-02-709 (20 kR), II- DGGV-7 × V-02-802 (20 kR), III- DGGV-2 $\times$ IPM-410(100 kR) and IV- DGGV-2 × SML-1815) $(100 \mathrm{kR})]$
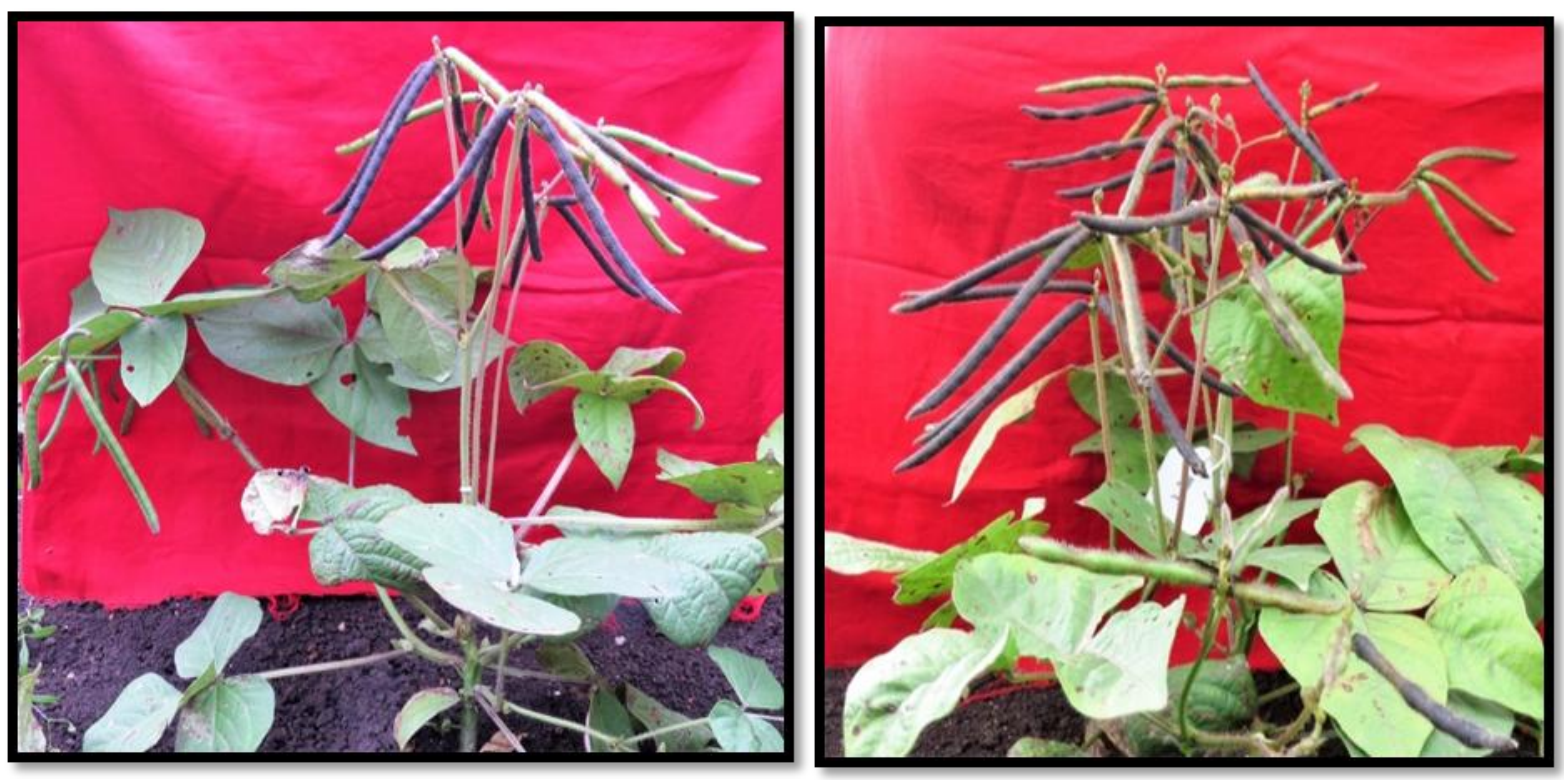

DGGV-7 × V-02-709 $(20 \mathrm{kR})$

DGGV-7 × V-02-802 (20 kR) 

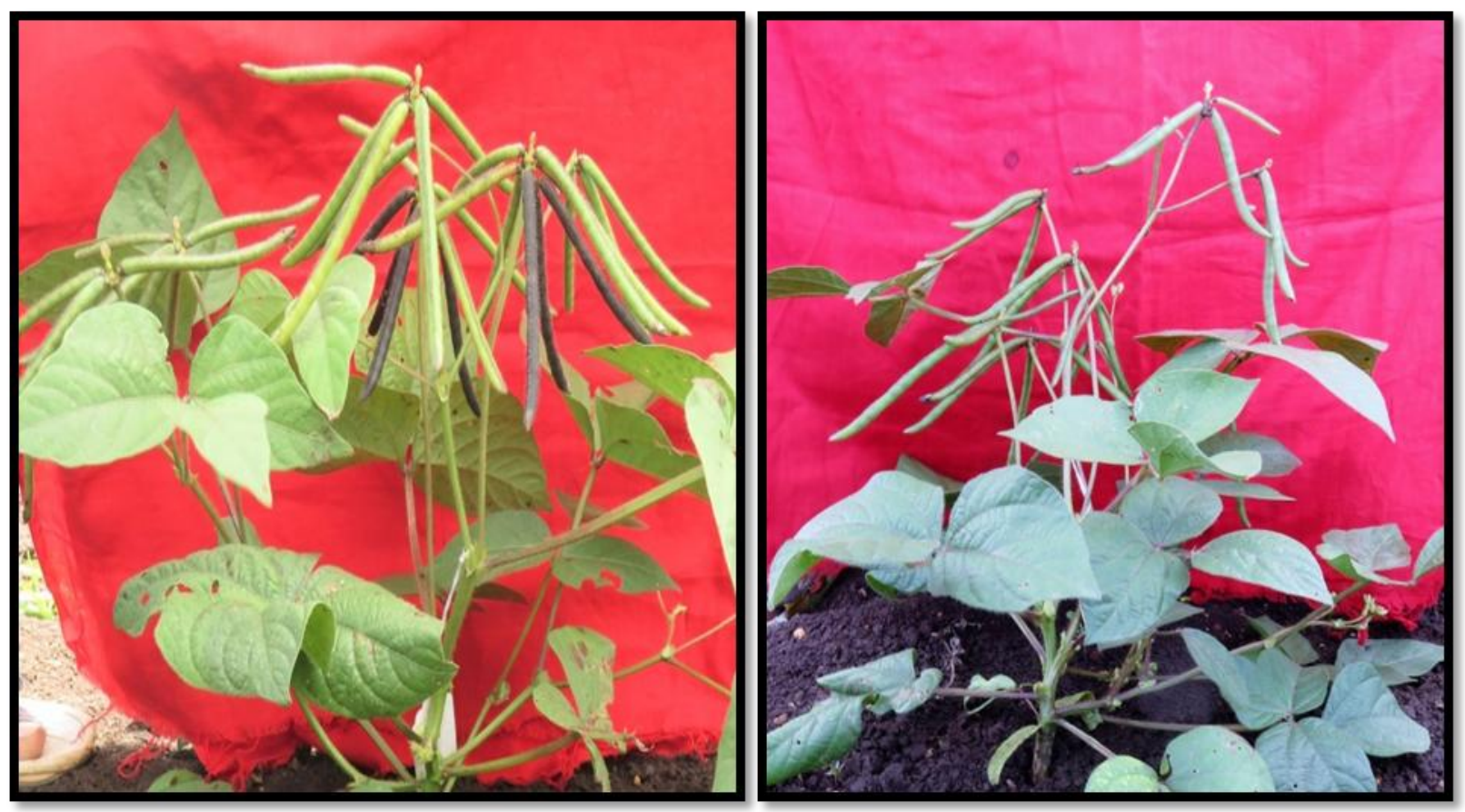

DGGV-2 $\times$ IPM-410-3 (100 kR)

DGGV-2 × SML-1815 (100 kR)

Fig.4 Superior putative mutants selected from $\mathrm{F}_{2} \mathrm{M}_{1}$ generation after gamma rays irradiation

In the present investigation, the mutagenic effectiveness was observed higher with $20 \mathrm{kR}$ in the breeding lines of DGGV-7 $\times \mathrm{V}-02-709$ and DGGV-7 $\times \mathrm{V}-02-802$ as compared to the dose $100 \mathrm{kR}$. Even though the dose $100 \mathrm{kR}$ was high for survival percentage, but it shown very vigorous plants as compared to $20 \mathrm{kR}$ (Fig 4). The mutagenic effectiveness was decreased with increased dose of mutagen, while the mutagenic efficiency was reported higher in lower dose of mutagen as the higher dose causes reduction in germination percentage and more lethal plants. Thus, gamma ray is an efficient and effective for creation of genetic variability in greengram for crop improvement.

\section{References}

Bashir, S., Wani, A. A. and Nawchoo, I. A. 2013. Mutagenic sensitivity of Gamma rays, EMS and Sodium azide in Trigonellafoenum-graecum L. Sci. Res. Repo., 3(1): 20-26.

Bhosale, S. S. and Kothekar, V. S. 2010. Mutagenic efficiency and effectiveness in clusterbean (Cyamopsis tetragonoloba (L.). J. Phytol., 2(6): 2127.

Dube, K. G., Bajaj, A. S. and Gawande,A. M. 2011.Mutagenic efficiency and effectiveness of gamma rays and EMS in Cyamopsis tetragonoloba (L.) Var. Sharada. Asiatic J. Biotech. Res., 2(4): 436-440.

Girija, M. and Dhanavel, D. 2009. Mutagenic Effectiveness and efficiency of gamma rays ethylmethanesulphonate and their combined treatments in cowpea (Vigna unguiculata L. Walp). Global J. Mol. Sci., 4(2): 68-75.

Gowda, C. L .L., Sunil, K. C., Gaur, P. M., 
Kumar, C. V. S. and Arvind, K. J. 2015. Pulses Research and Development Strategies for India. Pulses Handbook, pp. 17-27.

Khatri, A., Khan, I. A., Siddique, S. R. and Nizamani, G. S. 2005. Evaluation of high yielding mutants of Brassica junceacv. S-9 developed through gamma rays and EMS. Pak. J. Bot.,37: 279-284.

Konzak, C. F., Nilan, R. N., Wagner, J. and Faster, R. J. 1965.Efficient chemical mutagenesis in "The use of induced mutation in plant breeding", Radiation Bot., 5: 49-70.

Kumar, D. Sassi, Nepolean, T., Gopalan, A. 2003. Effectiveness and efficiency of the mutagens gamma rays and ethyl methane sulphonate on lima bean (Phaseolus lunatus L.), Indian $J$. Agril. Res., 37(2): 111-119.

More1, A. D. andBorkar, A. T. 2016. Mutagenic Effectiveness and Efficiency of Gamma Rays and EMS in Phaseolus vulgaris L. Inter. J. Curr.Microbiol. Applied Sci., 5(10): 544-554.

Mullainathan, L. and Umavathi, S., 2014, Induced mutagenesis in Cicer arietinum. Int.Let. Nat. Sci., 7: 1-4.

Patial, M., Thakur1, S. R. and Singh, K. P. 2015.Comparative

mutagenic effectiveness and efficiency of physical and chemical mutagen and induced variability in ricebean (Vigna umbellate).Legume Res., 38(1): 30-36

Rafiul, A. L. and Samiullah, K., 2017, mutagenic effectiveness and efficiency of gamma rays and $\mathrm{HZ}$ with phenotyping of induced mutations in lentil cultivars. Int.Let. Nat. Sci., 64(4): 17-31.

Sange, S. M., Mahamune, S. E., Kharat, S. N. and Kothekar, V. S. 2011.Effect of mutagenesis on germination and pollen sterility in pigeonpea. Bioscience Disco.,2: 2229-3469.

Sharma, S. K., Sood, R. and Pandey, D. P. 2005. Studies on mutagen sensitivity, effectiveness and efficiency in urdbean [Vigna mungo (L.)Hepper], Indian J. Genet., 65(1): 20-22.

Singh, A. K. and Singh, R. M. 2001. Mutagenic effectiveness and efficiency of gamma rays, ethyl methane sulphonate and their combination in Mung bean (Vigna radiata L. Wilczek), Crop Impro., 28(2): 260-266.

Tariq, A. S., Javid, I., Mohmmad, H. and Atta, B. 2008.Induced genetic variability in Chickpea.Pak. J. Bot., $606-613$.

\section{How to cite this article:}

Prasanta Kumar Majhi and Suma C. Mogali. 2020. Studies on Mutagenic Effectiveness and Efficiency of Gamma Rays in Greengram [Vigna radiata (L.) Wilczek]. Int.J.Curr.Microbiol.App.Sci. 9(03): 1475-1484. doi: https://doi.org/10.20546/ijcmas.2020.903.172 